\title{
A comparative analysis of the zona pellucida birefringence of fresh and frozen-thawed human embryos
}

\author{
Yi-Fan $\mathrm{Gu}^{1}$, Chang-Fu Lu ${ }^{1,2,3}$, Ge Lin ${ }^{1,2,3}$ and Guang-Xiu Lu ${ }^{1,2,3}$ \\ ${ }^{1}$ Institute of Reproductive and Stem Cell Engineering, Central South University, Xiangya Road 84, Changsha 410078, \\ People's Republic of China, ${ }^{2}$ Reproductive and Genetic Hospital of CITIC-XIANGYA, Changsha 410078, People's \\ Republic of China and ${ }^{3}$ National Engineering and Research Center of Human Stem Cell, Changsha 410078, People's \\ Republic of China
}

Correspondence should be addressed to G-X Lu at Institute of Reproductive and Stem Cell Engineering, Central South University; Email: lugxdirector@yahoo.com.cn

\begin{abstract}
The cryopreservation of human embryos is thought to induce alteration in the glycoprotein matrix and lead to zona change. However, this assumption has been full of controversies till now. The objective of this study was to evaluate the effect of cryopreservation on zona pellucida of human embryos. Fresh ( $n=106$, from 40 patients) and frozen-thawed embryos $(n=123$, from 40 patients) were obtained from consenting patients who received conventional IVF and ICSI treatment. The birefringence of zona pellucida in human fresh and frozen-thawed embryos was imaged and quantitatively analyzed using polarized light microscopy before embryo transfer. There was no significant difference in retardance and thickness of the zona pellucida multilaminar structure between the two groups. Pregnancy and implantation rates of transferred fresh and frozen-thawed embryos were also compared. No significant difference was found in the rates of clinical pregnancy (47.5 vs $37.5 \%)$ and implantation $(24.5$ vs $23.2 \%)$ between the two groups. This study suggests that there is no significant change in the zona pellucida birefringence of human embryos before and after cryopreservation.

Reproduction (2010) 139 121-127
\end{abstract}

\section{Introduction}

Zona pellucida is an extracellular matrix of mammalian oocyte and embryo, and plays different roles in fertilization and preimplantation development (Dean 1992). Zona pellucida is a multilaminar structure and composed of four glycoproteins (ZP1, ZP2, ZP3, and ZP4) in humans (Lefièvre et al. 2004), which are synthesized, secreted, and assembled during folliculogenesis (Wassarman 2008). These zona glycoproteins are assembled in a three-dimensional highly ordered filament structure in zona pellucida (Green 1997, Wassarman et al. 2004). During fertilization, sperm has to recognize and bind to zona, induce acrosome reaction, penetrate zona and fuse with oocyte membrane (Wassarman 2002). After fertilization, oocyte will release cortical granules (Sun 2003, Tsaadon et al. 2006) and induce the structure change in zona to prevent polyspermy (Moos et al. 1995). At the cleavage stage, the contact between the blastomeres is loose, so the main role of zona is to protect the embryos and maintain their integrity (Herrler \& Beier 2000). When they reach the blastocyst stage, embryos have to hatch out of zona and implant in endometrium (Gonzales et al. 2001). In vivo, hatching procedure is the result of interaction between blastocyst and uterus (Gonzales \& Bavister 1995), while in vitro, it is because of the tension of the periodic contraction and expansion, and enzymatic digestion of trophoblast (Schiewe et al. 1995b, Montag et al. 2000).

Since the first successful pregnancy following transfer of human frozen-thawed embryos (Trounson \& Mohr 1983), the cryopreservation of human embryos has been improved greatly and has become an efficient method to increase the accumulative outcome in human IVF programs (Hoffman et al. 2003). Carroll et al. (1990) suggested that the freeze-thawing process induced alteration in the glycoprotein matrix and led to zona change. Assisted hatching $(\mathrm{AH})$ is an artificial method to drill a hole in the zona to help blastocyst hatching. Considering the 'zona change' assumption, $\mathrm{AH}$ is also proposed to improve the implantation rate in frozen embryo transfer (FET) cycles (Cohen et al. 1991). To date, most researchers suggest that selective $\mathrm{AH}$ may have benefits to embryo implantation (Cohen et al. 1992). However, it is still controversial whether the cryopreservation procedure will change the structure of zona pellucida and $\mathrm{AH}$ is necessary to improve the implantation ability of frozen-thawed embryos (Veiga et al. 2004). Some researchers suggested that 
cryopreservation will induce zona change, so $\mathrm{AH}$ can increase the implantation of frozen-thawed embryos (Check et al. 1996, Tao \& Tamis 1997, Gabrielsen et al. 2004, Balaban et al. 2006, Ge et al. 2008), while other researchers have opposing views (Edirisinghe et al. 1999, Primi et al. 2004, Ng et al. 2005, 2008, Sifer et al. 2006).

Several techniques have been applied to identify this zona change. In the early stages, researchers selected the enzymatic digestion ( $\alpha$-chymotrypsin) method to quantitatively identify the change in human zona after fertilization (Schiewe et al. 1995a) and cryopreservation (Matson et al. 1997, Manna et al. 2001), but as the digestion time could be influenced by enzymatic activity and environmental factors (temperature and $\mathrm{pH}$ ), its precision was limited. Transmission electron microscopy (TEM) was applied to illuminate the ultrastructure of human zona after cryopreservation (Nottola et al. 2007, 2008). While electron microscopy requires samples to be fixed in advance, which lose further development potential after fixation, it cannot provide quantitative data about this zona change. Sun et al. (2003) developed a microelectromechanical systems-based multiaxis cellular force sensor, characterized mouse zona mechanical properties, and quantified the mechanical property differences of the zona before and after fertilization. Other force sensors were subsequently developed and applied to measure the mechanical behavior of zona pellucida in mouse (Murayama et al. 2006), human (Wacogne et al. 2008), and bovine (Papi et al. 2009a, 2009b). However, these force sensors were not commercially available in the clinic.

A polarized light microscope was developed to study the birefringence of living cells (Oldenbourg \& Mei 1995). The polarized light microscope uses novel electro-optical hardware and digital processing to image macromolecular structures in cells on the basis of their birefringence (an inherent physical property of highly ordered molecules; Oldenbourg 1996). There are two birefringent structures in human oocytes and embryos: spindle and zona pellucida. Polarized light microscopy has been employed for the noninvasive visualization of meiotic spindles in human oocytes (Wang et al. 2001a, 2001b), which proved no negative influence on the development potential of these oocytes and future embryos. Noninvasive polarized light microscope also provides an opportunity to investigate the structure of zona pellucida quantitatively in murine (Keefe et al. 1997, Silva et al. 1997) and human (Pelletier et al. 2004, Shen et al. 2005, Kilani et al. 2006, Rama Raju et al. 2007, Montag et al. 2008, Madaschi et al. 2009). To our knowledge, there is no quantitative analysis of zona pellucida birefringence of human embryos before and after cryopreservation to date.

Birefringence is an intrinsic property of human zona, which can be used to analyze the magnitude and orientation of zona molecular order (Oldenbourg 1996). In this study, we tested the hypothesis that the cryopreservation will change the structure of zona pellucida in human embryos. To test this assumption, this study quantitatively analyzed zona pellucida birefringence of fresh and frozen-thawed human embryos using polarized light microscopy. Better understanding of the cryopreservation effect on human zona pellucida will clarify whether the procedure would reduce implantation of human embryos due to zona change.

\section{Results \\ Multilaminar structure of human embryo zona pellucida}

The polarized light microscope (Polscope) is able to distinguish the multilaminar structure of human embryonic zona pellucida, which is inconspicuous with conventional Hoffmann optics. Obvious variance was observed in zona retardance and thickness between human embryos, even from the same patient (Fig. 1). According to Polscope system analysis, the innermost layer (IL) is the most birefringent and thickest layer of the human zona pellucida, and the orientation of filaments in this layer is radial; the retardance and thickness of outermost layer $(\mathrm{OL})$ are less, and the orientation of filaments is tangential; the thin middle layer (ML) exhibits minimal birefringent and the orientation of filaments is random (Table 1).
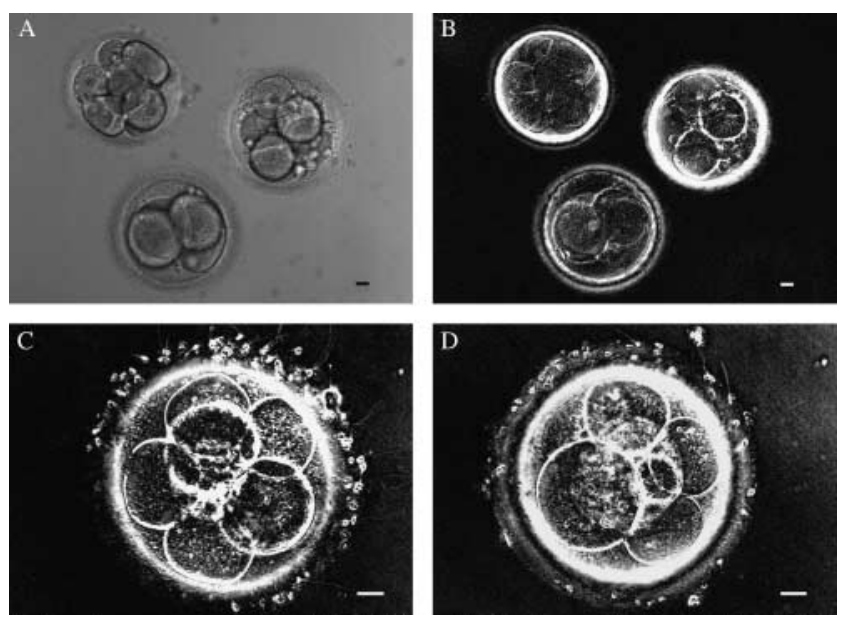

Figure 1 The birefringent zona pellucida of human embryos. (A) Zona pellucida of human embryos is inconspicuously imaged by conventional Hoffmann inverted microscope; (B) birefringent zona pellucida of human embryos can be imaged distinctly using polarized light microscopy, which is multilaminar and displays obvious variance between embryos; birefringent zona pellucida of fresh $(C)$ and frozenthawed (D) human embryos was analyzed using polarized light microscopy before embryo transfer. Scale bar $=10 \mu \mathrm{m}$. 
Table 1 Mean retardance magnitude and thickness of individual zone layers in human fresh and frozen-thawed embryos.

\begin{tabular}{lccl}
\hline & $\begin{array}{c}\text { Fresh } \\
\text { embryos }\end{array}$ & $\begin{array}{c}\text { Frozen- } \\
\text { thawed } \\
\text { embryos }\end{array}$ & P value \\
\hline $\begin{array}{c}\text { No. of patients } \\
\text { No. of embryos }\end{array}$ & 40 & 40 & - \\
$\begin{array}{c}\text { Zona inner layer } \\
\text { Retardance }(\mathrm{nm})\end{array}$ & 106 & 123 & - \\
$\quad \begin{array}{l}\text { Thickness }(\mu \mathrm{m}) \\
\text { Zona middle layer }\end{array}$ & $8.18 \pm 0.65$ & $3.12 \pm 0.72$ & 0.569 \\
$\quad$ Retardance $(\mathrm{nm})$ & $0.25 \pm 0.01$ & $0.25 \pm 0.02$ & 0.807 \\
$\quad \begin{array}{l}\text { Thickness }(\mu \mathrm{m}) \\
\text { Zona outer layer }\end{array}$ & $3.34 \pm 0.55$ & $3.28 \pm 0.51$ & 0.398 \\
$\quad$ Retardance $(\mathrm{nm})$ & $0.79 \pm 0.19$ & $0.79 \pm 0.20$ & 0.963 \\
$\quad \begin{array}{l}\text { Thickness }(\mu \mathrm{m}) \\
\text { Zona total thickness }(\mu \mathrm{m})\end{array}$ & $6.89 \pm 1.57$ & $6.78 \pm 1.72$ & 0.625 \\
\hline & $19.20 \pm 2.52$ & $18.99 \pm 2.48$ & 0.521 \\
\hline
\end{tabular}

Values are mean \pm S.D.

\section{Retardance and thickness of individual zona layers of human fresh and frozen-thawed embryos}

Retardance and thickness in individual zona layers of 106 fresh embryos and 123 frozen-thawed embryos were quantitatively analyzed using polarized light microscopy. The results showed no significant difference in mean retardance of individual layers of zona pellucida $\left(P_{\mathrm{IL}}=0.569, P_{\mathrm{ML}}=0.807, P_{\mathrm{OL}}=0.963\right.$; Table 1$)$ between the groups. Similar to the magnitude of retardance, the mean thickness of individual layers and total thickness did not differ significantly between the groups $\left(P_{\mathrm{IL}}=0.834\right.$, $P_{\mathrm{ML}}=0.398, P_{\mathrm{OL}}=0.625, P_{\mathrm{TOTAL}}=0.521 ;$ Table 1 ).

\section{Pregnancy and implantation rate of human fresh and frozen-thawed embryos}

In the fresh embryo group, 106 embryos from 40 patients were transferred, 19 patients became pregnant (19/40, $47.5 \%)$, and 26 embryos implanted (26/106, 24.5\%).

Table 2 Comparison of the characteristics and clinical outcomes of patients undergoing fresh or frozen embryo transfer cycles.

\begin{tabular}{|c|c|c|c|}
\hline & $\begin{array}{l}\text { Fresh } \\
\text { cycles }\end{array}$ & $\begin{array}{l}\text { Frozen } \\
\text { cycles }\end{array}$ & $P$ value \\
\hline No. of patients & 40 & 40 & - \\
\hline Age (years) & $29.8 \pm 4.1$ & $29.1 \pm 3.5$ & 0.419 \\
\hline Type of infertility (\%) & & & 0.179 \\
\hline Primary & $16(40.0)$ & $22(55.0)$ & \\
\hline Secondary & $24(60.0)$ & $18(45.0)$ & \\
\hline Cause of infertility (\%) & & & 0.612 \\
\hline Tubal & $29(72.5)$ & $26(65.0)$ & \\
\hline Male & $4(10.0)$ & 7 (17.5) & \\
\hline Mixed & $7(17.5)$ & $7(17.5)$ & \\
\hline Insemination procedure (\%) & & & 0.446 \\
\hline IVF & $31(77.5)$ & $28(70)$ & \\
\hline ICSI & $9(22.5)$ & $12(30)$ & \\
\hline \multicolumn{4}{|l|}{ Clinical outcomes (\%) } \\
\hline Clinical pregnancy & $19 / 40(47.5)$ & $15 / 40(37.5)$ & 0.366 \\
\hline Implantation & 26/106 (24.5) & 19/82 (23.2) & 0.829 \\
\hline
\end{tabular}

Values are number (\%) and mean \pm s.D.
In the frozen-thawed embryo group, 82 embryos from 40 patients were transferred, 15 patients were pregnant $(15 / 40,37.5 \%)$, and 19 embryos implanted (19/82, $23.2 \%)$. No significant difference was found in pregnancy $(P=0.366)$ and implantation rate $(P=0.829)$ between the groups (Table 2 ).

\section{Discussion}

In this study, the cryopreservation effect on the zona pellucida birefringence was quantitatively analyzed. Our result did not support the 'zona change' hypotheses and suggests that there is no significant change in the zona pellucida birefringence of human embryos before and after cryopreservation.

A zona change was first raised based on the studies of oocyte cryopreservation (Carroll et al. 1990). The authors found that frozen-thawed mouse oocytes had a reduced rate of fertilization when compared with unfrozen controls and suggested that freeze-thaw cycle induced zona change. Previous studies also found that cryopreservation increased the zona digestion time of mouse (Matson et al. 1997) and human (Manna et al. 2001) oocytes. After TEM, Nottola et al. $(2007,2008)$ showed that the amount and density of cortical granules appeared to be abnormally reduced in frozen-thawed human oocytes, and this feature was frequently associated with an increased density of the inner zona, possibly related to the occurrence of zona change. Thus, it may not be suitable to extend these results from oocyte cryopreservation on embryos, since cortical granules exist in mature oocytes, and this zona modification could not occur in frozen-thawed embryos in theory. The study of Matson et al. (1997) also showed that cryopreservation of embryos was not associated with zona change in dissolution time or reduced implantation.

This study implied that the conventional cryopreservation procedure could not be sufficient to influence the magnitude and orientation of the zona molecular order and change zona birefringence. The freeze-thaw procedure induces various cryodamages (osmotic shock and ice crystal formation) in human embryos (Pegg 2002). The structure of zona pellucida is composed of glycoproteins (with low amount of water) and could be more tolerable to cryodamages, while blastomeres of human embryos contain high amount of water, which are vulnerable in freeze-thaw procedure. Van den Abbeel \& Van Steirteghem (2000) reported that the incidence of zona pellucida damage was only $2.3 \%$ when embryos were frozen-thawed using plastic ministraw, although minor damage was not taken in consideration by these authors.

In fact, the term 'zona change' is a general description, and no method can measure each property of zona pellucida before and after cryopreservation. Enzymatic digestion method measures the zona solubility. 
Electron microscopy provides the ultrastructural information of zona pellucida. Cellular force sensor quantifies the zona mechanical properties. Polarized light microscopy analyzes the density (measured as retardance) and thickness of individual zona layers.

A clinical standard to describe the zona property could be the implantation of human embryos (Matson et al. 1997), which means that the embryos hatched from its zona and implanted in endometrium, although it is an indirect parameter. In this study, the implantation rate of human frozen-thawed embryos did not reduce after the freeze-thaw procedure. The result implied that cryopreservation did not affect human embryo hatching and implantation in vivo. Edgar et al. (2000) quantitatively analyzed the impact of cryopreservation on implantation potential of human early cleavage-stage embryos ( $n>5000)$, and the results showed that full intact thawed embryos had the same implantation potential $(11.3 \%)$ as their fresh counterpart $(11.4 \%)$, but partial intact thawed embryos had lower implantation rate $(6.2 \%)$. The authors concluded that blastomere loss was associated with the implantation potential reduction in human frozen-thawed embryos.

Although this study suggested that cryopreservation of human embryos did not overtly change zona birefringence, the results are not sufficient to answer whether $\mathrm{AH}$ is necessary for frozen cycles. The process of blastocyst hatching and implantation is the interaction of zona pellucida, trophoblast, and uterus in vivo. So considering whether $\mathrm{AH}$ is necessary for frozen-thawed embryos just based on the property of zona pellucida may bring biases. Cryodamages may lead to blastomere loss and reduce the cell number of trophoblast during blastocyst forming, and further impair the hatching ability of future blastocysts (Van Blerkom 1993).

This and other studies revealed multilaminar birefregent structure of human zona (Pelletier et al. 2004, Shen et al. 2005, Kilani et al. 2006, Rama Raju et al. 2007, Montag et al. 2008, Madaschi et al. 2009). Most data from this study were consistent with previous studies, except that the outer zona layer was thicker than that reported by Pelletier et al. $(3.7 \pm 1.4 \mu \mathrm{m})$. We suppose that two reasons may lead to this difference: first, the outer zona layer is especially variable (Fig. 1B), so it is not easy to define the boundary in some cases (it may rely on the observer's experience); secondly, we cannot exclude the ethnic differences in zona pellucida.

This is still a preliminary study. There are two variables: the source of the embryos (from different patients) and the state of the embryos (fresh and frozen). It would be a better experimental design to analyze the zona structure of the same human embryo before and after cryopreservation, due to the significant variance of zona pellucida. However, this is not easy to achieve in a clinical setting, as it means that all embryos would have to be marked, cryopreserved, stored, and thawed individually, making the freeze-thaw procedure much more complicated and which could have adverse influences on the clinical outcomes. Furthermore, the implantation rates could not be compared between paired samples in this experimental design. In future, we expect a randomized prospective experiment with larger sample size to obtain more reliable conclusions.

\section{Materials and Methods}

\section{Source of human embryos and patients' selection}

In this study, a total of 106 fresh embryos and 123 frozenthawed embryos at the cleavage stage were respectively obtained from 40 fresh cycle patients and 40 frozen cycle patients, who received conventional IVF and ICSI treatment in Reproductive and Genetic Hospital of CITIC-XIANGYA. Patients for both fresh and frozen-thawed embryo transfer cycles were included if they met the following criteria: 1) normal baseline endocrine parameters; 2) tubal or male infertility; 3) $<37$ years. The main characteristics of patients were not significantly different between the groups (Table 2), including age, type of infertility (primary or secondary), cause of infertility (tubal, male, or mixed) and insemination procedure (IVF or ICSI). Signed informed consent was obtained from these patients before performing the experiments. The study was approved by the ethics committee at the local hospital.

\section{IVF and embryo culture}

All patients underwent controlled ovarian stimulation induced by $\mathrm{rFSH}$ (Gonal-F, Serono), after pituitary downregulation by the administration of GNRH analogs (Leuprorelin, Takeda, Japan). GIII series culture system (Vitrolife, Göteborg, Sweden) was used for in vitro culture of human oocytes and embryos, according to the user's manual. On day 0 , oocyte retrieval was performed by ultrasound-guided transvaginal aspiration $36 \mathrm{~h}$ after hCG (5000 10 000 IU; Profasi, Serono) administration. Cumulus-oocyte complexes (COCs) were collected in $1 \mathrm{ml}$ G-FERT medium (Vitrolife) and cultured for 3-6 h to induce full maturation of oocytes.

In conventional IVF programs, the COCs were inseminated with prepared sperms (final concentration about $10^{5} / \mathrm{ml}$ ) and cultured in fresh G-FERT medium (2-3 COCs/1 ml) to the next day. In ICSI program, the COCs were briefly rinsed in $80 \mathrm{IU} / \mathrm{ml}$ hyaluronidase (Sigma Chemical Co.), and cumulus cells were removed by repeated gentle aspiration. Denuded oocytes were washed twice in fresh G-MOPS (Vitrolife) handling medium and performed ICSI according to standard protocol (Van Steirteghem et al. 1993). After ICSI, inseminated oocytes were cultured in G-FERT (10 $\mu \mathrm{l} / \mathrm{drop})$ till next day.

After fertilization evaluation on day 1, embryos were cultured in G1.3 (Vitrolife) medium (50 $\mu \mathrm{l} / \mathrm{drop}$ ) in groups (1-3 embryos/drop), according to the pronuclear scoring till day 3 .

All culture media were supplemented with $5 \%$ human serum albumin (HSA; Vitrolife), covered under paraffin oil (Vitrolife), and pre-equilibrated overnight. All oocytes and embryos were cultured at $37^{\circ} \mathrm{C}, 6 \% \mathrm{CO}_{2}, 5 \% \mathrm{O}_{2}$. 


\section{Assessment and selection of fresh embryo}

On day 1 (16-18 $\mathrm{h}$ postinsemination), fertilization assessment was performed according to the number, shape, and distribution of pronuclei and nucleoli (the pronuclear scoring system; Scott et al. 2000). Abnormal fertilization (NPN, 1PN, or $\geq 3 \mathrm{PN}$ ) may be as a result of zona dysfunction (Tarin et al. 1999), so all embryos in this study were normal fertilized zygotes (2PN).

On day 3 (66-68 h), morphology of fresh embryo was assessed, and fresh embryos were selected for transfer according to the conventional criteria (De Placido et al. 2002) in this study:

1) Normal fertilization;

2) Number of blastomeres is at least four;

3) Shape of blastomere is almost the same;

4) Fragments of embryos do not exceed 20\%;

5) Blastomere is transparent without serious cytoplasmic inclusion or vacuoles.

On day 3, 2-3 fresh embryos with highest morphology scores were selected for transfer. The other embryos accorded with these criteria were cryopreserved.

\section{Cryopreservation and thawing of human embryos}

The procedure of cryopreservation and thawing of human embryo were based on the method of Testart et al. (1986).

\section{Cryopreservation}

On day 3, fresh embryos ( $\geq 4$-cell, fragments $\leq 20 \%$ ) were cryopreserved using a programmable freezer (Kryo 360-1.7, Planer Products Ltd, Sunbury-On-Thames, UK) with Embryo Freeze-Kit 1 (Vitrolife) as cryoprotectant.

The components are as follows:

Cryo-PBS $=$ PBS with $25 \mathrm{mg} / \mathrm{ml} \mathrm{HSA}$.

Freeze solution 1 (FS1) $=1.5 \mathrm{M} \mathrm{PrOH}$ in Cryo-PBS

Freeze solution $2(\mathrm{FS} 2)=1.5 \mathrm{M} \mathrm{PrOH}+0.1 \mathrm{M}$ sucrose in Cryo-PBS

Briefly, all components were pre-equilibrated at room temperature $\left(25^{\circ} \mathrm{C}\right)$. Embryos were rinsed in $0.5 \mathrm{ml}$ Cryo-PBS and kept in FS1 for 10 min. Embryos were transferred into FS2, loaded (3 embryos/straw) into straws (Minitübe, Tiefenbach, Germany) immediately, and the $0.1 \mathrm{ml}$ FS2 containing embryos was sealed with air bubbles. The freezing program for embryos in our unit was as follows: starting temperature: $25^{\circ} \mathrm{C}$; rate of cooling: $-2{ }^{\circ} \mathrm{C} / \mathrm{min}$ from 25 to $-7{ }^{\circ} \mathrm{C}$; soak at $-7{ }^{\circ} \mathrm{C}$ for $5 \mathrm{~min}$; manual seeding; hold the temperature at $-7{ }^{\circ} \mathrm{C}$ for $10 \mathrm{~min}$; rate of cooling: $-0.3{ }^{\circ} \mathrm{C} / \mathrm{min}$ from -7 to $-30{ }^{\circ} \mathrm{C}$; rate of cooling: $-50{ }^{\circ} \mathrm{C} / \mathrm{min}$ from -30 to $-140{ }^{\circ} \mathrm{C}$. The frozen straw was quickly transferred from the freezing chamber to a reservoir of liquid nitrogen $\left(-196^{\circ} \mathrm{C}\right)$.

\section{Thawing}

Embryo Thaw-Kit 1 (Vitrolife) was used in the thawing procedure. The components are as follows:
Thaw solution $1(\mathrm{TS} 1)=1.0 \mathrm{MPrOH}+0.2 \mathrm{M}$ sucrose in Cryo-PBS

Thaw solution $2(\mathrm{TS} 2)=0.5 \mathrm{MPrOH}+0.2 \mathrm{M}$ sucrose in Cryo-PBS

Thaw solution $3(\mathrm{TS} 3)=0.2 \mathrm{M}$ sucrose in Cryo-PBS.

Briefly, all components were pre-equilibrated at room temperature $\left(25^{\circ} \mathrm{C}\right)$. Frozen embryos were thawed on the FET day at room temperature $\left(25^{\circ} \mathrm{C}\right)$ for $30 \mathrm{~s}$ and then at $30^{\circ} \mathrm{C}$ in a water bath for $30 \mathrm{~s}$. Subsequently, the cryoprotectant was removed by washing the embryos successively through TS1, TS2, TS3, and Cryo-PBS for 5 min respectively. And thawed embryos were transferred into G2.3 medium and cultured for 2-3 h before transfer.

\section{Assessment and selection of frozen-thawed embryos}

After thawing, frozen embryos were examined for the number and integrity of blastomeres and the degree of fragmentation, and graded according to the criteria of Veeck (1988). Embryos were classified as fully intact $(100 \%$ blastomeres survived), partially damaged ( $\geq 50 \%$ blastomeres survived), or degenerated ( $<50 \%$ blastomeres survived). Frozen-thawed embryos were considered to have survived if $\geq 50 \%$ of blastomeres were intact. Two or three survived frozen embryos with highest morphology scores (fully intact embryos were preferable) were selected for transfer. In this study, 123 embryos were thawed, 97 embryos (78.9\%) survived, including 52 fully intact embryos $(42.3 \%)$ and 45 partially damaged embryos $(36.6 \%)$, and 26 embryos $(21.1 \%)$ were degenerated.

\section{Embryo transfer and implantation confirmation}

On day 3, selected fresh embryos or frozen-thawed embryos were loaded in catheters (Wallace $1816 \mathrm{~N}$, Hythe, UK) with 20-25 $\mu$ G2.3 culture medium and transferred into patients' uteruses. Clinical pregnancy and implantation were confirmed by ultrasonic monitor (pregnant sac and fetal heat beat) 4 weeks after embryo transfer.

\section{Imaging and analysis of zona pellucida using polarized light microscopy}

To avoid the potential influence of in vitro culture on zona structure, all embryos were imaged on the day of embryo transfer, so the culture duration of both fresh and frozenthawed embryos was 3 days.

To image zona pellucida, each human embryo was placed in a $5 \mu$ l drop of G-MOPS (Vitrolife) handling medium covered with warm paraffin oil in a glass-bottomed $(0.17 \mathrm{~mm}$ thick) Petri dish (20 mm diameter; Delta TPG dish, Bioptechs, Butler, PA, USA). Embryos were examined with an inverted microscope (Nikon TE-2000U, Tokyo, Japan) equipped with Hoffman interference optics $20 \times$ objective lenses equipped with LC Polscope filters, analog video camera (COHU, Cambridge Research and Instrumentation, USA), and a personal computer (Dell, Round Rock, TX, USA) running image analysis software (LC-Polscope pro 4.4; Cambridge Research and Instrumentation, Woburn, MA, USA). Dishes were maintained at $37^{\circ} \mathrm{C}$ during examination 
with a thermal plate (IVF-1200, Pacific Contrast Co., San Diego, CA, USA) and objective heater (HT300, Minitübe). Alignment of the microscope and calibration of the software were performed before zona imaging. Zona pellucida was imaged five times by focusing at an equatorial plane of each embryo to ensure the accuracy of image representation of zona layers. Digital images were saved to a compact disk, and best images were selected for subsequent analysis.

Owing to significant variance in retardance and thickness of human zona, we used the analysis method of Pelletier et al. (2004) to ensure the accuracy and reproducibility. Briefly, eight points distributing evenly on zona (1-12 clock position) were sampled to measure the retardance and thickness of each layers (try to avoid the cumulus cells, sperms, and abnormal area on zona). We drew chords extending from the inner boundary of the zona outward, and collected retardance magnitude $\left(R_{i}\right.$, as retardance) at the midpoint and length ( $T_{i}$, as thickness) of each chord for each layer. Mean retardance $\left(\bar{R}=\left(\sum_{i=1}^{8} R_{i}\right) / 8\right)$ and thickness $\left(\bar{T}=\left(\sum_{i=1}^{8} T_{i}\right) / 8\right)$ for each layer were calculated and compared statistically.

All measurements were collected by the same observer. The duration of zona imaging was 2-5 min in each sample. The accuracy of thickness measurement in the Polscope system was calibrated with standard scale slide (Ronchi slide, $50 \mu \mathrm{m} / \mathrm{scale}$, Edmund Industrial Optics, Barrington, NJ, USA) prior to the experiment. To confirm the reproducibility and reliability of the image capture and analysis system, nine embryos from two patients were imaged and analyzed twice, and the results from two measurements showed highly correlated (the middle layer retardance was constantly as low as background value, which showed weak linear correlation).

\section{Statistical analysis}

The reproducibility test for Polscope system was performed using paired samples $t$-test. The characteristics of patients were compared between the groups using two-tailed Student's $t$-test and $\chi^{2}$ test where appropriate. The retardance and thickness of individual zona layers between the groups were quantitatively analyzed using two-tailed Student's $t$-test. The pregnancy and implantation rates between the groups were compared using $\chi^{2}$ test. Significance was considered as $P<0.05$.

\section{Declaration of interest}

All authors have no potential conflict of interest to disclose.

\section{Funding}

This study was supported by a grant from the Major State Basic Research Development Program of China (973 Program, No. 2007CB948103).

\section{Acknowledgements}

We are most grateful to the volunteers who devoted their embryos for Polscope imaging. We also thank staff in the CITIC-XIANGYA IVF center for their cooperation throughout the study.

\section{References}

Van den Abbeel E \& Van Steirteghem A 2000 Zona pellucida damage to human embryos after cryopreservation and the consequences for their blastomere survival and in vitro viability. Human Reproduction 15 373-378.

Balaban B, Urman B, Yakin K \& Isiklar A 2006 Laser-assisted hatching increases pregnancy and implantation rates in cryopreserved embryos that were allowed to cleave in vitro after thawing: a prospective randomized study. Human Reproduction 21 2136-2140.

Van Blerkom J 1993 Development of human embryos to the hatched blastocyst stage in the presence or absence of a monolayer of Vero cells. Human Reproduction 8 1525-1539.

Carroll J, Depypene H \& Mathews CD 1990 Freeze-thaw-induced changes of the zona pellucida explains decreased rates of fertilization in frozenthawed mouse oocytes. Journal of Reproduction and Fertility 90 547-553.

Check JH, Hoover L, Nazari A, O'Shaughnessy A \& Summers D 1996 The effect of assisted hatching on pregnancy rates after frozen embryo transfer. Fertility and Sterility $65254-257$.

Cohen J 1991 Assisted hatching of human embryos. Journal of In Vitro Fertilization and Embryo Transfer 8 179-190.

Cohen J, Alikani M, Trowbridge J \& Rosenwaks Z 1992 Implantation enhancement by selective assisted hatching using zona drilling of human embryos with poor prognosis. Human Reproduction 7 685-691.

Dean J 1992 Biology of mammalian fertilization: the role of the zona pellucida. Journal of Clinical Investigation 89 1055-1059.

Edgar DH, Bourne H, Speirs AL \& McBain JC 2000 A quantitative analysis of the impact of cryopreservation on the implantation potential of human early cleavage stage embryos. Human Reproduction 15 175-179.

Edirisinghe WR, Ahnonkitpanit V, Promviengchai S, Suwajanakorn S, Pruksananonda K, Chinpilas V \& Virutamasen P 1999 A study failing to determine significant benefits from assisted hatching: patients selected for advanced age, zonal thickness of embryos, and previous failed attempts. Journal of Assisted Reproduction and Genetics 16 294-301.

Gabrielsen A, Agerholm I, Toft B, Hald F, Petersen K, Aagaard J, Feldinger B, Lindenberg S \& Fedder J 2004 Assisted hatching improves implantation rates on cryopreserved-thawed embryos. A randomized prospective study. Human Reproduction 19 2258-2262.

Ge HS, Zhou W, Zhang W \& Lin JJ 2008 Impact of assisted hatching on fresh and frozen-thawed embryo transfer cycles: a prospective, randomized study. Reproductive Biomedicine Online 16 589-596.

Gonzales D \& Bavister BD 1995 Zona pellucida escape by hamster blastocysts in vitro is delayed and morphologically different compared with zona escape in vivo. Biology of Reproduction 52 470-480.

Gonzales DS, Bavister BD \& Mese SA 2001 In utero and in vitro proteinase activity during the Mesocricetus auratus embryo zona escape time window. Biology of Reproduction 64 222-230.

Green DP 1997 Three-dimensional structure of the zona pellucida. Reviews of Reproduction 2 147-156.

Herrler A \& Beier HM 2000 Early embryonic coats: morphology, function, practical applications. An overview. Cells, Tissues, Organs 166 233-246.

Hoffman DI, Zellman GL, Fair CC, Mayer JF, Zeitz JG, Gibbons WE \& Turner TG Jr 2003 Cryopreserved embryos in the United States and the availability for research. Fertility and Sterility 79 1063-1069.

Keefe D, Tran P, Pellegrini C \& Oldenbourg R 1997 Polarized light microscopy and digital image processing identify a multilaminar structure of the hamster zona pellucida. Human Reproduction 12 1250-1252.

Kilani SS, Cooke S, Kan AK \& Chapman MG 2006 Do age and extended culture affect the architecture of the zona pellucida of human oocytes and embryos? Zygote 14 39-44.

Lefièvre L, Conner SJ, Salpekar A, Olufowobi O, Ashton P, Pavlovic B, Lenton W, Afnan M, Brewis IA, Monk M et al. 2004 Four zona pellucida glycoproteins are expressed in the human. Human Reproduction 19 1580-1586.

Madaschi C, Aoki T, de Almeida Ferreira Braga DP, de Cássia Sávio Figueira R, Semião Francisco L, laconelli A Jr \& Borges E Jr 2009 Zona pellucida birefringence score and meiotic spindle visualization in relation to embryo development and ICSI outcomes. Reproductive Biomedicine Online 18 681-686. 
Manna C, Rienzi L, Greco E, Sbracia M, Rahman A, Poverini R, Siracusa G \& De Felici M 2001 Zona pellucida solubility and cortical granule complements in human oocytes following assisted reproductive techniques. Zygote 9 201-210.

Matson PL, Graefling J, Junk SM, Yovich JL \& Edirisinghe WR 1997 Cryopreservation of oocytes and embryos: use of a mouse model to investigate effects upon zona hardness and formulate treatment strategies in an in vitro fertilization programme. Human Reproduction 12 1550-1553.

Montag M, Koll B, Holmes P \& van der Ven H 2000 Significance of the number of embryonic cells and the state of the zona pellucida for hatching of mouse blastocysts in vitro versus in vivo. Biology of Reproduction 62 1738-1744.

Montag M, Schimming T, Köster M, Zhou C, Dorn C, Rösing B, van der Ven H \& Ven der Ven K 2008 Oocyte zona birefringence intensity is associated with embryonic implantation potential in ICSI cycles. Reproductive Biomedicine Online 16 239-244.

Moos J, Faundes D, Kopf GS \& Schultz RM 1995 Composition of the human zona pellucida and modifications following fertilization. Human Reproduction 10 2467-2471.

Murayama Y, Mizuno J, Kamakura H, Fueta $Y$, Nakamura H, Akaishi K, Anzai K, Watanabe A, Inui H \& Omata S 2006 Mouse zona pellucida dynamically changes its elasticity during oocyte maturation, fertilization and early embryo development. Human Cell 19 119-125.

Ng EH, Naveed F, Lau EY, Yeung WS, Chan CC, Tang OS \& Ho PC 2005 A randomized double-blind controlled study of the efficacy of laserassisted hatching on implantation and pregnancy rates of frozen-thawed embryo transfer at the cleavage stage. Human Reproduction 20 979-985.

Ng EH, Lau EY, Yeung WS, Cheung TM, Tang OS \& Ho PC 2008 Randomized double-blind comparison of laser zona pellucida thinning and breaching in frozen-thawed embryo transfer at the cleavage stage. Fertility and Sterility 89 1147-1153.

Nottola SA, Macchiarelli G, Coticchio G, Bianchi S, Cecconi S, De Santis L, Scaravelli G, Flamigni C \& Borini A 2007 Ultrastructure of human mature oocytes after slow cooling cryopreservation using different sucrose concentrations. Human Reproduction 22 1123-1133.

Nottola SA, Coticchio G, De Santis L, Macchiarelli G, Maione M, Bianchi S, laccarino M, Flamigni C \& Borini A 2008 Ultrastructure of human mature oocytes after slow cooling cryopreservation with ethylene glycol. Reproductive Biomedicine Online 17 368-377.

Oldenbourg R 1996 A new view on polarization microscopy. Nature $\mathbf{3 8 1}$ 811-812.

Oldenbourg R \& Mei G 1995 New polarized light microscope with precision universal compensator. Journal of Microscopy 180 140-147.

Papi M, Brunelli R, Sylla L, Parasassi T, Monaci M, Maulucci G, Missori M, Arcovito G, Ursini F \& De Spirito M 2009a Mechanical properties of zona pellucida hardening. European Biophysics Journal DOI: 10.1007/s00249-009-0468-3.

Papi M, Sylla L, Parasassi T, Brunelli R, Monaci M, Maulucci G, Missori M, Arcovito G, Ursini F \& De Spirito M 2009b Evidence of elastic to plastic transition in the zona pellucida of oocytes using atomic force spectroscopy. Applied Physics Letters 94153902.

Pegg DE 2002 The history and principles of cryopreservation. Seminars in Reproductive Medicine 20 5-13.

Pelletier C, Keefe DL \& Trimarchi JR 2004 Noninvasive polarized light microscopy quantitatively distinguishes the multilaminar structure of the zona pellucida of living human eggs and embryos. Fertility and Sterility 81 850-856.

De Placido G, Wilding M, Strina I, Alviggi E, Alviggi C, Mollo A, Varicchio MT, Tolino A, Schiattarella C \& Dale B 2002 High outcome predictability after IVF using a combined score for zygote and embryo morphology and growth rate. Human Reproduction 17 2402-2409.

Primi MP, Senn A, Montag M, Van der Ven H, Mandelbaum J, Veiga A, Barri P \& Germond M 2004 A European multicentre prospective randomized study to assess the use of assisted hatching with a diode laser and the benefit of an immunosuppressive/antibiotic treatment in different patient populations. Human Reproduction 19 2325-2333.

Rama Raju GA, Prakash GJ, Krishna KM \& Madan K 2007 Meiotic spindle and zona pellucida characteristics as predictors of embryonic development: a preliminary study using PolScope imaging. Reproductive Biomedicine Online 14 166-174.
Schiewe MC, Araujo E Jr, Asch RH \& Balmaceda JP 1995a Enzymatic characterization of zona pellucida hardening in human eggs and embryos. Journal of Assisted Reproduction and Genetics 12 2-7.

Schiewe MC, Hazeleger NL, Sclimenti C \& Balmaceda JP 1995b Physiological characterization of blastocyst hatching mechanisms by use of a mouse antihatching model. Fertility and Sterility 63 288-294.

Scott L, Alvero R, Leondires M \& Miller B 2000 The morphology of human pronuclear embryos is positively related to blastocyst development and implantation. Human Reproduction 15 2394-2403.

Shen Y, Stalf T, Mehnert C, Eichenlaub-Ritter U \& Tinneberg HR 2005 High magnitude of light retardation by the zona pellucida is associated with conception cycles. Human Reproduction 20 1596-1606.

Sifer C, Sellami A, Poncelet C, Kulski P, Martin-Pont B, Bottero J, Porcher R, Cedrin-Durnerin I, Hugues JN \& Wolf JP 2006 A prospective randomized study to assess the benefit of partial zona pellucida digestion before frozen-thawed embryo transfers. Human Reproduction 21 2384-2389.

Silva CP, Silva V, Kommineni K \& Keefe D 1997 Effect of in vitro culture of mammalian embryos on the architecture of the zona pellucida. Biological Bulletin 193 235-236.

Van Steirteghem AC, Nagy Z, Joris H, Liu J, Staessen C, Smitz J, Wisanto A \& Devroey P 1993 High fertilization and implantation rates after intracytoplasmic sperm injection. Human Reproduction 8 1061-1066.

Sun QY 2003 Cellular and molecular mechanisms leading to cortical reaction and polyspermy block in mammalian eggs. Microscopy Research and Technique 61 342-348.

Sun Y, Wan KT, Roberts KP, Bischof JC \& Nelson BJ 2003 Mechanical property characterization of mouse zona pellucida. IEEE Transactions on Nanobioscience 2 279-286.

Tao J \& Tamis R 1997 Application of assisted hatching for 2-day-old frozenthawed embryo transfer in a poor-prognosis population. Journal of Assisted Reproduction and Genetics 14 128-130.

Tarin JJ, Trounson A \& Sathananthan H 1999 Origin and ploidy of multipronuclear zygotes. Reproduction, Fertility, and Development 11 273-279.

Testart J, Lassalle B, Belaisch-Allart J, Hazout A, Forman R, Rainhorn JD \& Frydman R 1986 High pregnancy rate after early human embryo freezing. Fertility and Sterility 6 268-272.

Trounson A \& Mohr L 1983 Human pregnancy following cryopreservation, thawing and transfer of an eight-cell embryo. Nature 305 707-709.

Tsaadon A, Eliyahu E, Shtraizent N \& Shalgi R 2006 When a sperm meets an egg: block to polyspermy. Molecular and Cellular Endocrinology 252 107-114.

Veeck LL 1988 Oocyte assessment and biological performance. Annals of the New York Academy of Sciences 541 259-274.

Veiga A, Boiso I \& Belil I 2004 Assisted hatching. In Text Book of Assisted Reproductive Techniques, edn 2, pp 181-189. Eds DK Gardner, A Weissman, CM Howles \& Z Shoham. London and New York: Taylor \& Francis Group.

Wacogne B, Pieralli C, Roux C \& Gharbi T 2008 Measuring the mechanical behaviour of human oocytes with a very simple SU-8 micro-tool. Biomedical Microdevices 10 411-419.

Wang WH, Meng L, Hackett RJ \& Keefe DL 2001 a Developmental ability of human oocytes with or without birefringent spindles imaged by Polscope before insemination. Human Reproduction 16 1464-1468.

Wang WH, Meng L, Hackett RJ, Odenbourg R \& Keefe DL $2001 b$ The spindle observation and its relationship with fertilization after intracytoplasmic sperm injection in living human oocytes. Fertility and Sterility 75 348-353.

Wassarman PM 2002 Sperm receptor and fertilization in mammals. Mount Sinai Journal of Medicine 69 148-155.

Wassarman PM 2008 Zona pellucida glycoproteins. Journal of Biological Chemistry 283 24285-24289.

Wassarman PM, Jovine L \& Litscher ES 2004 Mouse zona pellucida genes and glycoproteins. Cytogenetic and Genome Research 105 228-234.

Received 3 June 2009

First decision 13 July 2009

Revised manuscript received 24 August 2009

Accepted 4 September 2009 